\title{
Achieving Social IT Alignment through the Orchestration of IT Assets: An Interpretive Case Study
}

\section{Claudia Pelletier , Anne-Marie Croteau, Louis Raymond \& Dragos Vieru}

To cite this article: Claudia Pelletier , Anne-Marie Croteau , Louis Raymond \& Dragos Vieru (2021) Achieving Social IT Alignment through the Orchestration of IT Assets: An Interpretive Case Study, Information Systems Management, 38:1, 42-61, DOI: 10.1080/10580530.2020.1733712

To link to this article: https://doi.org/10.1080/10580530.2020.1733712

曲 Published online: 10 Mar 2020.

Submit your article to this journal $\pi$

III Article views: 184

Q View related articles $\asymp$

View Crossmark data $₫$

Citing articles: 1 View citing articles 지 


\title{
Achieving Social IT Alignment through the Orchestration of IT Assets: An Interpretive Case Study
}

\author{
Claudia Pelletier ${ }^{\mathrm{a}}$, Anne-Marie Croteau ${ }^{\mathrm{b}}$, Louis Raymond (10), and Dragos Vieru ${ }^{\mathrm{c}}$
}

aÉcole de gestion, Université du Québec à Trois-Rivières, Trois-Rivières, QC, Canada; bJohn Molson School of Business, Concordia University, Montréal, QC, Canada; 'Technologies de l'information, Université TÉLUQ, Québec, QC, Canada

\section{ABSTRACT}

Adopting a qualitative approach, this exploratory case study analyzes the path to social IT alignment (SITA) of a small and medium-sized enterprise (SME) that operates in the industrial services sector and is engaged in an organizational IT-enabled transformation. Based on three mechanisms, namely allocating, structuring, and coordinating IT resources, the findings of this study illuminate how a small, yet collaborative organization may achieve SITA through IT asset orchestration mechanisms that are better understood and managed.

\section{KEYWORDS}

Social IT alignment; IT asset orchestration mechanism;

IT-enabled transformation;

IT alignment process; SME

\section{Introduction}

Misalignment between the firm's information technology (IT) capabilities and its social structures hinders the attainment of its technological, operational and strategic goals (Benbya, Leidner, \& Preston, 2019). To avoid such negative outcomes, the firm must enact a continuous IT alignment process through rearrangements that, directly and indirectly, support its digital transformation strategy (Besson \& Rowe, 2012). Reich and Benbasat (2000, p. 82) define the social dimension of IT alignment as "the state in which business and IT executives within an organizational unit understand and are committed to the business and IT mission, objectives, and plans". The determinants of this alignment are likely to be processes such as communication and planning (Reich \& Benbasat, 1996), that may also significantly affect the internal and external relationships of the firm (Chi, Zhao, George, Li, \& Zhai, 2017; Majchrzak, Jarvenpaa, \& Bagherzadeh, 2015). Moreover, the successful realization of an IT-enabled transformation is obtained not only by using the firm's existing IT resources efficiently and effectively but also by developing and deploying new IT resources and competencies (Levina, 2005; Turner, Swart, \& Maylor, 2013). It has been founded that in many cases, these new IT capabilities may be developed by the firm in collaboration with other organizations (Vrontis, Thrassou, Santoro, \& Papa, 2017).

An IT-enabled transformation is a complex undertaking for the firm as it must manage several dimensions of IT alignment, chief among these is the social dimension (Diirr \& Cappelli, 2018; Ragowsky, Licker,
\& Gefen, 2012). Consequently, the firm's business and IT strategies will be affected (Tanriverdi, Rai, \& Venkatraman, 2010), and issues and questions will arise with regard to the IT competencies and knowledge that must be acquired and developed by the firm, be it by itself or in collaboration with its business partners (Dyer \& Kale, 2007). This is particularly true of small and medium-sized enterprises (SMEs) that are constantly challenged about their IT resources competencies (Levy, Loebbecke, \& Powell, 2003; Raymond, Bergeron, \& Croteau, 2013). These enterprises must thus develop and deploy an evolving "capability for productive use of IT towards users' and organizations' goals" (Ragowsky et al., 2012, p. 150). In turn, a SME must operate within an IT alignment dynamic that allows it to identify, integrate and manage shared IT competencies and knowledge in ways that support the attainment of its strategic goals (Diirr \& Cappelli, 2018).

The above considerations on the IT alignment process and the IT-enabled transformation of the firms give rise to three research issues of both theoretical and practical relevance. First, the values, communications, and shared understanding among business and IT actors in a "social" perspective of alignment are more than ever topics of interest for researchers (Benbya et al., 2019; Reich \& Benbasat, 2000). Second, it is now required for practitioners to have access to further knowledge concerning the "how" of the IT alignment phenomenon, including insights to better comprehend and manage the social 
dimension of the IT alignment process (Tallon, Queiroz, Coltman, \& Sharma, 2016), and in particular to better orchestrate their firm's IT assets within this process (Sirmon, Hitt, Ireland, \& Gilbert, 2011). Consequently and thirdly, IS researchers may be further encouraged to analyze the IT alignment phenomenon from a "processbased" - rather than outcome-based - perspective (Langley, Smallman, Tsoukas, \& Van de Ven, 2013; Pentland, 1999).

For the past two decades, researchers are called upon to deepen the "social" dimension of the alignment process, that is, social IT alignment (SITA) (Benbya et al., 2019; Reich \& Benbasat, 1996, 2000). One is concerned here with relational and exchange mechanisms mobilized as well as the IT capabilities developed by the firm, both internally and externally in collaboration with other organizations (Diirr \& Cappelli, 2018; Queiroz, Coltman, Sharma, Tallon, \& Reynolds, 2012). In this vein, Henderson and Venkatraman (1993) made it clear that alignment is "not an event but a process of continuous adaptation and change" (p. 473). Nevertheless, whereas previous studies on strategic IT alignment have mainly focused on financial and other organizational performance outcomes (Benbya et al., 2019; Chan \& Reich, 2007; Robey, Im, \& Wareham, 2008), less attention has been given to revealing "how" organizations may successfully achieve collaboration and social IT alignment concretely (Chi et al., 2017; Raisch, 2008). Moreover, while achieving social IT alignment is crucial for SMEs in general (Raymond et al., 2013), it is especially critical for the ones that must constantly experiment and combine knowledge for innovation and service purposes (Vrontis et al., 2017).

There is however a gap in the literature with regard to SITA for IT-enabled transformation, as prior IS studies have focused more on the "content" rather than the "process" of IT alignment (Reynolds \& Yetton, 2015; Tarafdar \& Qrunfleh, 2009), on technological "fit" rather than how firms concretely orchestrate their IT resources (Jansen, Tempelaar, Van den Bosch, \& Volberda, 2009; Sirmon et al., 2011), and on the measure of alignment impacts rather than on the organization of IT activities to produce superior value for the firm (Benbya et al., 2019; Reynolds \& Yetton, 2015). There is also a theory-practice gap with regard to SITA, as prior studies have neglected to propose specific guidelines for managing the IT alignment process in general (Chan \& Reich, 2007), and the SITA process in particular (Benbya et al., 2019; Reich \& Benbasat, 1996, 2000). Hence, there is no clear understanding of the way in which the firm's internal social structures (e.g., shared IT vision) interrelate with its external structures (e.g., shared IT competencies and knowledge) (Gibson \& Birkinshaw, 2004; Robey et al., 2008). Furthermore, the orchestration mechanisms related to the SITA process remain underexplored (Chan \& Reich, 2007; Croteau, Léger, \& Cassivi, 2008; Reynolds \& Yetton, 2015), including the dynamics of the alignment activities and practices within this process (Cao, Mohan, Ramesh, \& Sarkar, 2014).

Given the above gaps in researchers' knowledge and practitioners' know-how with regard to the social dimension of IT alignment, we need further identification and understanding of the specific mechanisms that trigger and impact collaborative efforts within the SITA process (Im \& Rai, 2014; Robey et al., 2008). The aim here is to better understand how to favor IT alignment through shared learning and mutual adjustments (Benbya et al., 2019), including the adjustments that insures the firm's present and future success in its business environment (El Sawy \& Pavlou, 2008). Ultimately, for firm's managers as well as the other internal actors within the alignment process, this means being able to translate IT strategies into concrete actions (Feurer, Chaharbaghi, Weber, \& Wargin, 2000; Tallon et al., 2016).

Anchored in the evolutionary root of the resourcebased view (RBV) and in the dynamic capabilities approach (Barney, Ketchen, \& Wright, 2011; Helfat et al., 2007), the asset orchestration framework was used as the lens through which the firm's SITA process was to be observed and analyzed (Sirmon et al., 2011). This framework was chosen because of its theoretical and practical usefulness (Sirmon, Hitt, \& Ireland, 2007), given that "to be successful [...] leaders must be able to orchestrate the allocation of resources between the old and new business domains" (O’Reilly \& Tushman, 2013, p. 332). Given this choice, our two research questions are formulated as follows:

Q1: What are the IT asset orchestration mechanisms that enable the social IT alignment process of IT-based service SMEs?

Q2: How do IT-based service SMEs mobilize these IT orchestration mechanisms to enact their social IT alignment process?

The two research objectives that ensue from these questions are: 1) to identify the IT asset orchestration mechanisms that allow an organization to enact a SITA process, and 2) to explore how these mechanisms interact with other IT-related processes and structures in an IT-based service SMEs context. In order to achieve these objectives, we conducted an exploratory case study whose unit of analysis is the SITA process of 
a Canadian SME operating in the IT-based services sector, that is, a process examined within the context of a single firm (Pentland \& Feldman, 2005). Moreover, the SITA process was analyzed at two levels, that is, at the organizational and interorganizational levels (Klein, Dansereau, \& Hall, 1994).

Our case data analysis suggests that SITA for ITenabled transformation is a multilevel phenomenon that is facilitated by three recurrent orchestration mechanisms: allocating IT resources, structuring IT resources and coordinating IT resources. From a practical point of view, the results of this study demonstrate concretely how the proper management of the SITA process is founded on the exchange and sharing of IT competencies and knowledge.

The rest of the paper is structured as follows: We first present the theoretical background and the analytical framework that underlie and guide our study of the SITA process. We next present our interpretive case study method, followed by the presentation of the case itself. We follow with a discussion of the case study's results and present our contribution to the theory and practice of IT alignment. We conclude with avenues for future research on the SITA process.

\section{Theoretical background}

The strategic IT alignment process is essentially meant to allow the firm to reposition itself in its business environment, notably by rearranging its IT infrastructure (Henderson \& Venkatraman, 1993). Nevertheless, there has been little research on the precise mechanisms by which IT alignment is concretely achieved, including with its different units, competitors and/or business partners (Chan \& Reich, 2007; Queiroz et al., 2012; Reynolds $\&$ Yetton, 2015). This understudied aspect of IT alignment concerns its social dimension (Benbya et al., 2019; Reich \& Benbasat, 1996, 2000). The same is true of the adjustment mechanisms for managing the exchange and sharing of IT competencies and knowledge (Diirr \& Cappelli, 2018; Dyer \& Kale, 2007), be they internal or external to the firm (Vrontis et al., 2017).

\section{Social IT alignment}

In prior SITA studies, efforts have been made to characterize and explain the business relationships life-cycle in strategic alliances (Croteau et al., 2008), the integration and management of shared elements in cross-organizational context (Diirr \& Cappelli, 2018), the benefits of business-tobusiness relationships (Kelly \& Scott, 2012), as well as the drivers of sustainable alignment in multi-business organizations (Reynolds \& Yetton, 2015). However, few studies have really looked into crucial elements of the SITA process such as the internal and external communication and cooperation mechanisms used by the firm to link its IT strategy to its business strategy (Benbya et al., 2019; Reich \& Benbasat, 2000). Otherwise, researchers have found that SITA depends on inter-firm collaboration (Knoben \& Oerlemans, 2006), on knowledge acquisition and coordination (Vrontis et al., 2017) and on intra- and inter-firm alignment practices and structures (Diirr \& Cappelli, 2018; Raymond et al., 2013).

The SITA process may be partly revealed by identifying the IT resources and competencies as well as the relational capabilities that are needed to successfully implement a digital transformation strategy (Besson \& Rowe, 2012; Dyer \& Kale, 2007; Dyer \& Singh, 1998). First, note that the firm's IT resources are defined here as an ensemble of ITrelated assets as well as the practices and competencies that enable managers to mobilize and deploy these assets (Piccoli \& Ives, 2005). The firm's IT assets refer to its investment in IT, that is, in endowing itself with a set of ITrelated means such as IT personnel and computer hardware and software (Aral \& Weil, 2007). Second, SITA relationships suppose "agreements to provide and use the available (physical and informational) resources" (Diirr \& Cappelli, 2018, p. 150). Third, the involved organizations must co-align through structures wherein "needs and ability to process have to be synchronized" (Croteau et al., 2008, p. 146). Fourth, a firm must address IT-related changes that occur in their relationships with its business partners (Majchrzak et al., 2015). Indeed, these changes may impact its IT-enabled transformation processes and structures (Chang, Hughes, \& Hotho, 2011; Thorgren, Wincent, \& Örtqvist, 2012), and new business strategies may emerge from the attribution of a more strategic role to IT (Reynolds \& Yetton, 2015; Tanriverdi et al., 2010).

In summary, the IT alignment literature, particularly concerning its "social" dimension, has some large gaps (Benbya et al., 2019; Chan \& Reich, 2007; Queiroz et al., 2012). These gaps principally include the relational processes and capabilities that enable a firm to access other organizations' IT resources and competencies (Dyer \& Kale, 2007; Reynolds \& Yetton, 2015), as well as the specific mechanisms that are involved (Tallon et al., 2016; Turner et al., 2013). Despite some notable efforts, several questions are still unanswered, with regard in particular to the understanding of the exchange mechanisms that enable the SITA process.

\section{IT-enabled transformation through social IT alignment}

The firm's digital transformation strategy undoubtedly rests on a broader linkage than the functional and 
structural alignment of various systems and technologies (Ragowsky et al., 2012; Robey et al., 2008). More precisely, in the wake of Tanriverdi et al. (2010), Reynolds and Yetton (2015) indicate that the particular context of SITA raises "the need to reframe the extant models of alignment" (p. 101). In this regard, ITenabled transformation through SITA means that the organization will be "qualitatively" different as well as its deep structures will be transformed (Besson \& Rowe, 2012). In order to better understand the more precise mechanisms of this profound transformation, the literature proposes different perspectives, of which we will retain the following three: a) capabilities perspective; b) learning perspective, and c) ambidexterity perspective.

From a capability-based view (Helfat et al., 2007), the SITA process is meant to support the firm in the reconfiguration of its existing operational capabilities through the development of new products and/or new IT applications to match the needs of a changing business environment. Founded upon the prior work of Teece and others (Teece, Pisano, \& Shuen, 1997), four organizational activities have been identified in this regard: 1) sensing; 2) learning; 3) integrating knowledge, and 4) coordinating (El Sawy \& Pavlou, 2008). In a more specific context of multi-business organizations, the mechanisms by which IT alignment mechanisms create value are: 1) governance, 2) competence, and 3) flexibility (Reynolds \& Yetton, 2015). In their review of literature on alliances, Dyer and Kale (2007) have reported that these relationships are characterized by a) the creation of relationshipspecific assets, b) an access to complementary capabilities, c) a substantial flow of knowledge between partners, and d) the presence of effective governance mechanisms. Moreover, the capabilities perspective provides an explanation on "how barriers to erosion [such as organizational learning and asset stock accumulation] can be maintained and strengthened over time" (Piccoli \& Ives, 2005, p. 751).

From an organizational learning perspective, the SITA process is viewed as a relational phenomenon, which refers to the development of a form of cospecialization between IT specialists and users with regard to IT (Dyer \& Singh, 1998). As such, collaborative relationships with other organizations allow firms to combine resources and share knowledge and risks, optimize asset use, increase market power and attractiveness of products and services, or capitalize on opportunities for organizational learning (Barringer \& Harrison, 2000). This is especially crucial when critical resources or key technological activities for the firm and its operations stand outside its organizational boundaries (Dyer \& Singh, 1998; Vrontis et al., 2017). This includes when IT resources are drivers of the firm's innovation performance or are required as input to the services offered by the firm (CegarraNavarro \& Dewhurst, 2007; Thorgren et al., 2012). Moreover, in order to characterize how knowledge is shared between firms within specific collaborative environments, Loebbecke, van Fenema, and Powell (2016) have identified four types of knowledgesharing mechanisms: 1) structural, 2) procedural, 3) technical, and 4) social mechanisms.

The ambidexterity perspective refers to the necessity for an organization to both exploit existing resources and explore new ones (O'Reilly \& Tushman, 2013) in order to compete in markets where efficiency and incremental improvement are valued and where flexibility and experimentation are required (Jansen et al., 2009). With regards to the SITA process, prior studies have shown that simultaneous sharing of both exploitative and explorative knowledge leads to better relationship performance. Yet, these studies have not demonstrated 'how' such ambidexterity was attained and managed (Cao et al., 2014), including the manner by which IT alignment is realized in its social dimension (Diirr \& Cappelli, 2018; Im \& Rai, 2014; Kauppila, 2010). More specifically, ambidexterity embodies the idea that enduring success of a firm depends on its ability to exploit current IT resources while concurrently exploring new opportunities as it reconfigures its IT resources to obtain a competitive advantage (Chi et al., 2017; March, 1991).

\section{Social IT alignment in the SMEs context}

The above observations concerning the complexity of the SITA process, as well as the need to better understand this process, are coherent with the need to reveal the reality of a digital transformation strategy in the SME context. Indeed, given the specificities of these firms, and particularly knowledge-intensive ones (Vrontis et al., 2017), they must often simultaneously co-operate and compete with other firms ('coopetition') (Levy et al., 2003; Ribeiro-Soriano \& Urbano, 2009). To cope with this situation, SMEs must integrate and manage the shared knowledge and resources in a way that supports the attainment of their strategic goals (Diirr \& Cappelli, 2018). In this regard, there is a consensus that organizations need to both explore and exploit successfully their "coopetition" to thrive (Gibson \& Birkinshaw, 2004; Raisch, 2008; Turner et al., 2013). More specifically, within the SITA process, being ambidextrous facilitates the firm's access to IT artifacts, competencies and knowledge that may be found in its external environment (Vrontis et al., 2017). 
Now, as an IT-enabled transformation process is based on social relationships and not exclusively on IT artifacts, it seems reasonable to assume that SMEs engaged in a collaborative process need an organizational structure that balances both exploration and exploitation with regard to their IT resources (Besson \& Rowe, 2012; Dyer \& Singh, 1998). In other words, facing the challenges of a digitized world where IT are the tools that connect business activities and interorganizational relationships (Tanriverdi et al., 2010), SMEs are increasingly in need of specialized IT resources that are accessible in their business environment (CegarraNavarro \& Dewhurst, 2007). Effective IT management requires these organizations to focus on the relational (Dyer \& Singh, 1998), collaboration (Majchrzak et al., 2015) and coordination dimensions of their exchanges with external business partners (Williams \& Karahanna, 2013), that is, to develop shared capabilities, knowledge as well as exploitative and explorative activities.

In summary, although motivated by a variety of reasons leading to different outcomes (Barringer \& Harrison, 2000), the social dimension of IT alignment is based primarily on the sharing of IT artifacts whose development will be done collectively, but management and subsequent use may be more or less formalized and standardized (Markus, Steinfield, Wigand, \& Minton, 2006). In doing so, it was observed that the management of exchanges and relationships could be more or less centralized (Williams \& Karahanna, 2013) and that the nature of the collaboration could vary widely (Diirr \& Cappelli, 2018), especially in the different maturity levels of IT structures, IT processes and IT artifacts held and used by partners (Croteau et al., 2008). In the SMEs context, this also means that the combination as well as the accumulation of various resources through the exchanges and the interactions of the firm with its business partners are means to achieve increased innovation and renewed products and services in the specific context of SMEs (Cegarra-Navarro \& Dewhurst, 2007; Levy et al., 2003; Thorgren et al., 2012). However, the specific mechanisms by which SMEs, their managers as well as other internal actors initiate, manage and sustain the SITA process for purposes of IT-enabled transformation have yet to be identified and analyzed.

\section{IT asset orchestration mechanisms for social IT alignment}

Based on the above argumentation, we suggest that an integrative theoretical lens is required to better understand how a SITA process emerges and is managed by the firm (Besson \& Rowe, 2012; Majchrzak et al., 2015; Vrontis et al., 2017). In the past, some authors have suggested that understanding the appropriate mechanisms for balancing tensions, autonomy and synergy between internal actors as well as external partners is still an understudied topic (Brown, 1999; Williams \& Karahanna, 2013), arguing that there is a lack of knowledge about the collaborative mechanisms that trigger and affect the contextualized efforts made within such a process (Levina, 2005; Markus et al., 2006). Recognizing the complexity of the studied phenomenon, we propose to investigate how these mechanisms relate to each other and interact with other IT-related processes and structures (Jansen et al., 2009; Prasad, Green, \& Heales, 2012), that is, through IT asset orchestration mechanisms (Sirmon et al., 2007).

Concerning the social dimension of IT alignment, the asset orchestration concept is deemed theoretically useful because it explicitly addresses how managerial actions contribute to adapt and change the resources and structures required between various actors engaged in an economic activity, be they internal or external (Helfat et al., 2007). Asset orchestration is a dynamic approach that goes beyond the classic value, rarity, inimitability, and non-substitutability characteristics of the RBV (Barney et al., 2011; Sirmon et al., 2011). Thus, asset orchestration mechanisms in a SITA context are defined as "shared capabilities and organizational routines that can enable firms to access the resources and capabilities of other partners [...] to permit transfer, recombination and/or creation of knowledge" (Helfat et al., 2007, p. 69). As such, the attention is redirected on the "underexplored processes (i.e., the 'black box') that lie between resources" to explain how these resources can be managed by both partners to create superior value (Sirmon et al., 2007, p. 288).

In combination with the capabilities, learning and ambidexterity perspectives of IT-enabled transformation, the asset orchestration concept provides a practical perspective to delve into the deeper structures of the SITA process in many ways. First, it offers a dynamic framework to study a processual and complex phenomenon that is constantly evolving (Robey et al., 2008), within which internal actors as well as external partners co-produce and share knowledge (Maritan \& Brush, 2003). Second, through the investigation of different levels of IT-enabled transformation, the asset orchestration approach fosters better components identification as well as a greater understanding of the SITA processes by highlighting how intangible resources such as shared IT knowledge and tangible resources such as shared IT artifacts relate to each other (Jin \& Robey, 2008). Third, it underscores the 
importance of relational capabilities, and of IT-enabled capabilities in particular, for the success of the SITA management process (Im \& Rai, 2014; Markus et al., 2006; Prasad \& Green, 2016). Finally, it enables a more accurate identification of the mechanisms at work, by allocating, structuring, and coordinating resources at different action levels (Helfat et al., 2007; Sirmon et al., 2011).

In summary, the benefits of an effective management of the SITA process are often not visible or definable at first (Reich \& Benbasat, 1996, 2000). Nevertheless, SMEs must address the ensuing changes that occur in their organization (Majchrzak et al., 2015). More specifically, they must do so with regard to the organizational transformation enabled by their use of IT, including transformations to their internal and external exchanges and relationships (Chang et al., 2011; Vrontis et al., 2017).

\section{Analytical framework}

In the digital era, the common thread in relationships between internal actors and external partners is that they all depend on and make use of IT resources and competencies in a collaborative environment (Majchrzak et al., 2015; Prasad et al., 2012). In this regard, exploring and exploiting new knowledge through IT-enabled collaboration and coordination are particularly relevant in the context of SMEs (Vrontis et al., 2017). Notably, because simultaneous co-operation and competition ("coopetition") between two or more organizations may often be observed (Levy et al., 2003; Ribeiro-Soriano \& Urbano, 2009). This also means that, in certain contexts, business exchanges and alliances may be formed for motives and benefits other than externalization (Kelly \& Scott, 2012; Lavie \& Rosenkopf, 2006), that is, to achieve coherent capability configurations, organizational learning and ambidexterity (Barringer \& Harrison, 2000; Cegarra-Navarro \& Dewhurst, 2007).

In line with our research objectives, the analytical framework presented in Figure 1 aims at 1) providing a better identification of the specific IT asset orchestration mechanisms that compose the SITA process, and 2) to explore how these mechanisms interact with other IT-related processes and structures in the digital transformation context of the studied firm. Following the research initiated by Reich and Benbasat (1996) on the social dimension of IT alignment, our initial conjecture is that the SITA process implies different levels of activities as well as various exchanges to adequately support the IT-enabled transformation in progress. Our second conjecture is that the management of a SITA process must be based on specific IT asset orchestration mechanisms between decision makers, IT professionals and users in all of the involved organizations (Sirmon et al., 2011).

The first orchestration mechanism, the resources allocating mechanism is defined as the set of activities for using technological, financial, material and/or human resources in order to build value within the firm and between the firm and its business partners (Gilbert, 2005). With regards to IT artifacts, allocating resources is particularly important because "assets are not automatically allocated to their first best use" (Helfat et al., 2007, p. 22). Notably because the value of these artifacts, including the IT skills and competencies that accompany them, depends on complementary and/or co-specialized assets and capabilities owned by the involved partners (Maritan \& Peteraf, 2011). Second, the resources structuring mechanism enables the intra- and inter-firm configuring and assembling of technological, financial, material and/ or human resources (Helfat et al., 2007; Sirmon et al., 2011). The SITA process can best be described in terms of sub-processes that initially stabilize and enrich existing IT as well as non-IT resources, and then develop new resources in order to improve organizational capabilities (Sirmon et al., 2011). Third, the resources coordinating mechanism refers to "managerial activities supporting assembling and reassembling firms' complementary and co-specialized resources (Helfat et al., 2007, p. 25) [...] It also involves communication routines that allow to disseminate information and/or warn conflict between partners" (p. 73). This mechanism thus involves subprocesses that mobilize, coordinate and deploy previously developed capabilities. The aim of coordinating resources is to support competitive value creation (Sirmon et al., 2007, 2011), including better IT knowledge-sourcing capabilities (Vrontis et al., 2017).

In addition to these specific mechanisms, we distinguish two levels of activities to enable and manage the SITA process for IT-enabled transformation. Founded on an evolutionary mode of change that is based on the variation, selection and retention processes (Van de Ven \& Poole, 1995), the initial analytical element in the SITA framework is the firm's IT vision and IT artifacts, to be progressively shared internally (Raymond et al., 2013). More specifically, the first level of the SITA process is where the decisions are made to avoid being rendered irrelevant by changes in markets and technologies. In this regard, sharing the same IT vision and artifacts facilitates the initiation of the exchanges between internal actors (Jin \& Robey, 2008). We also conjecture that these structures are the anchor point that contextualizes future collaborative processes (Heracleous \& Barrett, 2001). Thus, the 
lower part of the SITA framework represents the second level of IT-enabled transformation. It includes the processes and sub-processes that result from recursive mechanisms based on various social and relational capabilities (Markus et al., 2006; Van de Ven \& Poole, 1995). In this context, we thus refer to the deeper structures of the SITA process. These structures are defined as the shared IT competencies and knowledge that enable the enactment of this process (Gersick, 1991; Kauppila, 2010). In our view, this represents a kind of results and/or effects of the sub-processes previously associated to allocating, structuring and coordinating mechanisms (Sirmon et al., 2011), as well as observable events and actions (Heracleous \& Barrett, 2001), especially through managerial and/or collaborative activities (O'Reilly \& Tushman, 2013; Prasad \& Green, 2016). Following Besson and Rowe (2012), we deem these outcomes to be the "qualitative" representations of the "deep structures" that have been modified throughout the SITA process.

\section{Case study research method}

In order to obtain "deep insights" on a complex phenomenon as well as to capture all the richness of the situation under investigation (Klein \& Myers, 1999; Miles, Huberman, \& Saldaña, 2014), this exploratory research focuses on how a SITA process for IT-enabled transformation is enacted by the firm. In line with recent calls made by IS researchers (Benbya et al., 2019; Reynolds \& Yetton, 2015; Tallon et al., 2016), special attention is thus paid to the multilevel exchanges and actions that occur through the transformation at different levels of the firm. In particular, we focus our attention on the IT asset orchestration mechanisms that are mobilized in order to enact the social IT alignment process required for such a transformation.

Founded on a qualitative research approach through a single-case study method (Yin, 2009), we adopt an interpretive position that is not only recognized in the IS field (Klein \& Myers, 1999; Miles et al., 2014) but is also consistent with the "understanding of dynamics present in single settings" (Eisenhardt, 1989, p. 534). As used here, the single-case study method is a research strategy meant to obtain initial insights (Walsham, 1995).

With regard to our research objectives, the case study method in an interpretive stance is appropriate for many reasons. First, because it emphasizes social construction and reveals the validity and usefulness of our theorization in a specific context (Eisenhardt \& Graebner, 2007; Klein \& Myers, 1999). Second, through qualitative interviews that are theoretically driven
(Miles et al., 2014; Myers \& Newman, 2007), a case study founded on identifying and understanding IT asset orchestration mechanisms is meant to 'reveal' and explain the SITA process within the firm's digital transformation strategy. In other words, an interpretive single-case study is an open door to a future cross-case analysis (Miles et al., 2014) that has the potential to raise us "above the idiosyncratic case" (Siggelkow, 2007, p. 21). Coherent with an exploratory purpose (Walsham, 1995), our use of theory and existing concepts (Figure 1) follows Eisenhardt's (1989) proposed categorization in that it serves as an initial guide for the research design and data collection.

\section{Case selection and description}

Case selection was made by theoretical sampling in order to maximize the case study's potential for discovery (Eisenhardt \& Graebner, 2007; Yin, 2009). With regard to the research questions, potential cases were thus evaluated on the basis of the firm's management of the SITA process (Ribeiro-Soriano \& Urbano, 2009) as well as on the nature of its exchanges about shared IT artifacts with at least one of its business partners. More specifically, this meant that the choices of participants [two persons: owner-manager and IT manager], episodes [four different moments between November 2013 and June 2014], and interactions [an IT-based service SME in relation with its longest-standing partner] was "driven by a conceptual question, not by a concern for representativeness" (Miles et al., 2014, p. 33). Following Siggelkow's (2007) recommendations, the selected case for this research provides analytical insights on what went on throughout a SITA process that covers a twelve-year period (1999-2012), and particularly on the management of this process through IT asset orchestration mechanisms. Respecting these criteria, the selected case was a company that we shall name CallCenter (alias to preserve confidentiality). This firm is a Canadian SME specialized in web survey services and other tailor-made automated solutions for marketing and commercial research.

CallCenter was originally founded as a training service for a private Canadian college in 1999. CallCenter's activities were dedicated to support the practical component of a training program on online customer services through the exploitation of an outbound call center. In 2003, CallCenter was spun off. The newly created company gradually reoriented its activities toward more specialized marketing services. Managed by its sole owner and reaching approximately 1 million outgoing calls a year, CallCenter is a SME that has been enjoying steady growth ever since, and it now has fifty 


\section{SOCIAL IT ALIGNMENT PROCESS (SITA)}

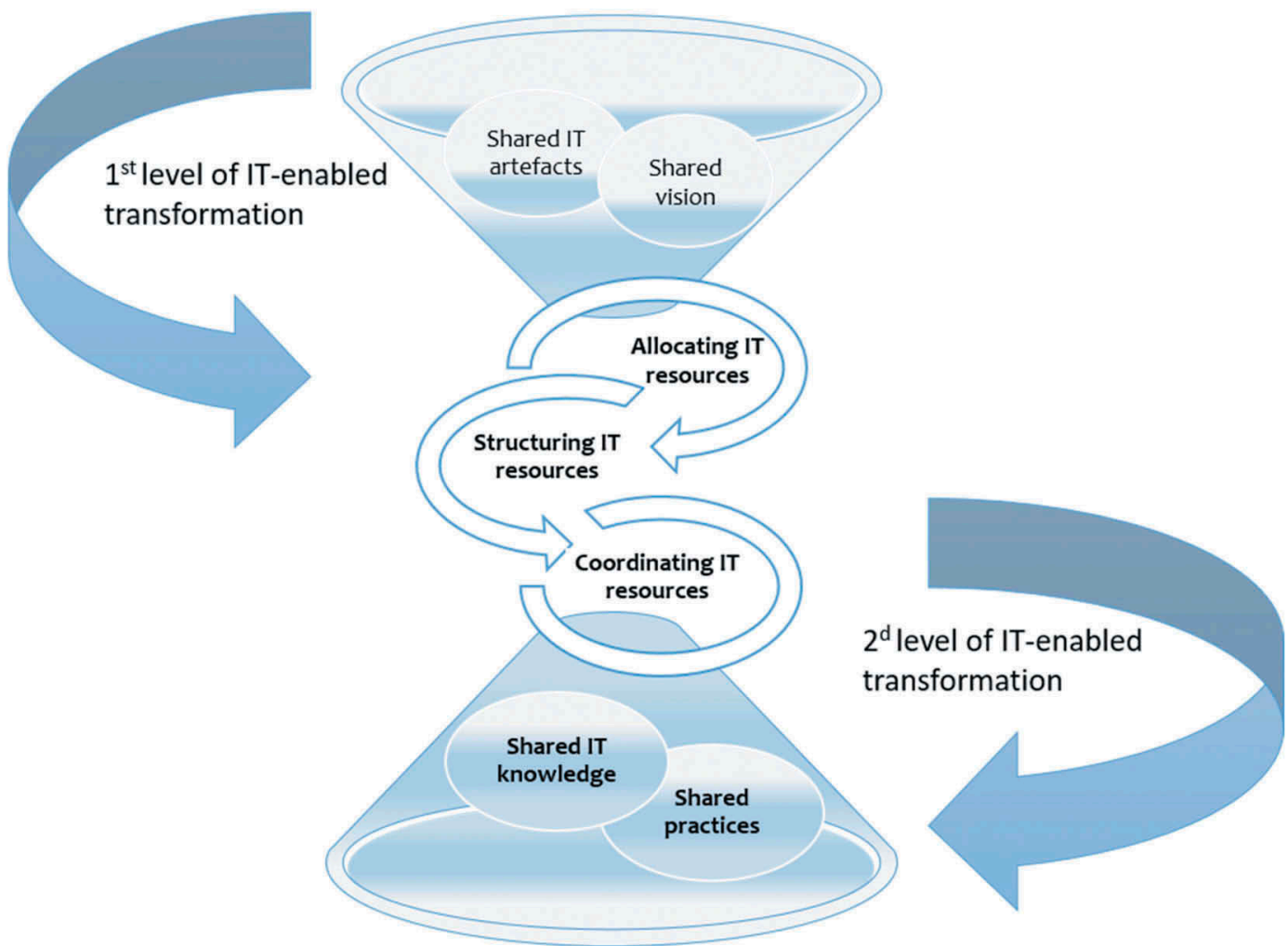

Figure 1. Analytical framework.

employees. Exclusively using the systems developed by ISPartner, an outside firm with whom it has had a longstanding relationship, CallCenter's competitive environment is almost totally composed of large enterprises. These firms are also going thought major changes such as an increasing use of IT and other specialized software applications as well as the integration of different modes of intervention that were formerly independent from each other (e.g. in/outbound call centers and web/ phone survey services) (Chou, 2011; Jack, Bedics, \& McCary, 2006).

\section{Data collection and analysis}

Data were collected through semi-structured interviews that were conducted with the firm's owner-manager and IT manager. These key-informants of the case were met individually on four different occasions between November 2013 and June 2014 for initial, complementary and validation interviews, for a total of approximately six hours, thus generating more than forty pages of transcriptions. Framed by a research protocol that established informant selection criteria, means of contact, ethical considerations, including data recording and transcription, the two initial interviews were conducted using two complementary semi-structured guides (management or IT personnel), while subsequent interviews were based on preliminary data analysis and research notes. Following Myers and Newman (2007) guidelines for qualitative interviews, the data collection procedure was meant to "situate" all the actors, including the interviewer, decrease the possibility of social dissonance, and ensure flexibility as well as openness to "surprises". To strengthen triangulation (Yin, 2009) and in line with the "multiple interpretations principle" (Klein \& Myers, 1999), data collection was completed with press releases and articles, online archival documents concerning company's structure, services, business partners, as well as its realized projects over the years. Allowing the use of multiple sources in various formats such as web pages and pdf/docx documents, the NVivo qualitative data analysis software was used for data transcription and codification.

For coding purposes, we explored the case data by using the vocabulary related to the concepts of capability, learning and ambidexterity as well as to asset orchestration mechanisms. In doing so, we sought to leverage the "conceptual unity" as well as the "unified 
structure" of our data analysis procedures (Miles et al., 2014). The coding scheme is presented in Table 1; furthermore, coding examples of interview extracts are presented in Table 2 in order to illustrate the application of the coding scheme.

The 'Sources' column (cf. Fichiers) in Table 1 indicates the number of documents within which elements relative to the SITA process have been identified. Note that each element was identified from at least three sources, that is, by the same individual at three different moments, or by two different individuals and at different moments. The 'References' column (cf. Références) indicates the number of references that were associated to each of the codes that were retained for the data analysis. Considering that codes and sub-codes are also related to each other in such a context (Saldaña, 2015), the same extract could be coded in more than one category. Note in this regard that the number of references associated to a code ranged from 16 ('Structuring mechanism') to 77 ('Shared-IT artifacts').

Our analysis was performed in two steps. First, we performed a descriptive analysis on both pre-identified and emergent dimensions of the different levels of the SITA process, including the firm's internal and external social structures. Second, from the case data extracts originally selected, we sought to identify the emerging IT asset orchestration mechanisms implemented by CallCenter to support its external relationships, mainly with its software supplier and principal business partner, ISPartner (also an alias). This second coding step was made by following a process-analytical approach (Pentland, 1999) which relies on an explanation building logic for sequencing cumulative mechanisms such as resource allocating, structuring and coordinating (Langley et al., 2013; Yin, 2009). At the end of the analysis procedures and following Klein and Myers (1999) "dialogical principle", we decided to consider extracts of two coding categories ("Practices about collaboration (capabilities)" and "HR and relational capabilities") as being equivalent.

Adopting an abductive logic coherent with a "causal" explanation approach (Eisenhardt \& Graebner, 2007; Williams \& Karahanna, 2013), our analysis principally focused on CallCenter's social structures at different levels of transformation and on the IT asset orchestration mechanisms mobilized by the firm in enacting its SITA process. Following Saldaña (2015), we thus applied two principles of the axial coding method that allow to: 1) explore the properties and dimensions such as contexts, conditions, interactions, and consequences of a SITA process, and 2) relate codes and sub-codes to each other. In order to reinforce our interpretations of CallCenter's SITA process, a representative "chain of evidence" (Yin, 2009) (with other interview extracts) is presented in Appendix A.

\section{Case study}

In the context of an IT-based knowledge-intensive services sector, the CallCenter case is meant to illustrate and explain a process of constant and high-added value adaptation to a rapidly changing business environment (Vrontis et al., 2017). More specifically, it reveals the social dimension of the IT alignment process required for the efficient and effective provision of services in this context, including the mobilization of IT asset orchestration mechanisms meant to enable this process (Chang et al., 2011). To support our description and explanation the dynamics of alignment, that is, to unveil "temporality, activity, and flow" within the IT alignment process (Langley et al., 2013), a visual mapping of CallCenter's SITA process is presented in Figure 2. This mapping is meant to illustrate the process "story" narrated below (Pentland, 1999), and in particular to map CallCenter's IT-enabled transformation through its IT alignment process as well as the IT asset orchestration mechanisms at work in this process.

\section{CallCenter's 1st level of IT-enabled transformation: internal SITA}

In 2001, CallCenter's main business partner, ISPartner, started to develop and support a set of survey software solutions for data collection in different languages, through various modes (phone, web, mobile, and interactive). As of

Table 1. Data coding scheme.

\begin{tabular}{|c|c|c|c|c|}
\hline & & Nom & Fichiers & Références \\
\hline \multirow{3}{*}{$\square-$} & 0 & $1^{\text {st }}$ level of IT-enabled transformation & 0 & 0 \\
\hline & |- - & Shared-IT artifacts & 4 & 77 \\
\hline & -- - & Shared-vision & 4 & 32 \\
\hline \multirow{4}{*}{-- } & 0 & $2^{\text {nd }}$ level of IT-enabled transformation & 0 & 0 \\
\hline & -- - & HR and relational capabilities & 4 & 20 \\
\hline & -- - & Practices about collaboration (capabilities) & 4 & 33 \\
\hline & + - - & Processes about knowledge (learning) & 3 & 22 \\
\hline-- & 0 & Allocating mechanism & 4 & 24 \\
\hline-- & 0 & Coordinating mechanism & 3 & 21 \\
\hline |- - & ○ & Structuring mechanism & 4 & 16 \\
\hline
\end{tabular}


Table 2. Coding examples of CallCenter's interview extracts.

\begin{tabular}{|c|}
\hline \\
\hline Shared IT-artifacts \\
\hline $\begin{array}{l}\text { [Developed by ISPartner] The Command Center software [allows] us to truly 'manage' the projects.. [...] It's the tool that encompasses } \\
\text { all of the call center for the management of telephony. [...] We have a server that links SQL with Pronto [also developed by } \\
\text { ISPartner]. We have a server for the firewall. We have a domain server that controls all of the network here, the workstations.. [...] } \\
\text { (source: IT manager - December } 6,2013 \text { ) }\end{array}$ \\
\hline Shared Vision \\
\hline $\begin{array}{l}\text { This is what I am trying to do with [IT Manager], to inculcate to him, in addition to the technical aspect on which he is very strong, } \\
\text { a more strategic aspect, to think outside the box.. That is not always evident and I think I would not have been able to succeed if } \\
\text { I had not, one day, put a finger in the pie.. (source: Owner-manager - November 28, 2013) } \\
\text { We don't even go into the details of the tasks because we go through stages that we already know and that are always the same... } \\
\text { That varies, yes, by project.. But that... in the end.. we didn't take the time to totally formalize, as we acquired a hyper-simple tool } \\
\text { named WonderList. We now use this application because, intuitively, we know what we must do at each stage and this tool allows us } \\
\text { to only formalize the main stages and to share these elements with the whole team. (source: Owner-manager - February 4, 2014) }\end{array}$ \\
\hline ASSET ORCHESTRATION MECHANISMS \\
\hline Allocating $\mathrm{r}$ \\
\hline $\begin{array}{l}\text { In 2013, the decision was made to develop high-level solutions. As we increase our needs at the transactional level, we are there. [...] } \\
\text { We invested heavily in equipment to enhance the security of our internet access. [...] Now, customers are increasingly demanding, } \\
\text { which requires us to do more important things to ensure business continuity. (source: Owner-manager - June 14, 2014) } \\
\text { [...] Technologically speaking, I think, we surpass competitors, even the biggest ones. [...] (source: IT manager - December 6, 2013) }\end{array}$ \\
\hline Structuring mechanism \\
\hline $\begin{array}{l}\text { [Our services are] a box and now it's a mixed box [...] that brings us to services.. more integrated.. that we manage to put the three } \\
\text { services together, i.e. pure phone, web and IVR. In fact, we are not renewing the service itself, but the way we offer it. (source: Owner- } \\
\text { manager - February 4, 2014) }\end{array}$ \\
\hline Coordinating mechanism \\
\hline $\begin{array}{l}\text { There is now a lot of outsourcing going on in our field and it's made much easier when you're on the same platform [In this case], } \\
\text { there are no changes to the databases and there is also a capacity for the subcontractor to report on time, } 30 \text { minutes, } 24 \text { hours.. to } \\
\text { whoever grants the contract, without significant changes. There is therefore perfect continuity and perfect control from the donor to } \\
\text { the one who operates the mandate. (source: Owner-manager - November 28, 2013) } \\
\text { We have all the information that emanates from the projects. Thus, I know (in approximately } 32 \text { seconds) where I am with regard to } \\
\text { billable hours in a project. (source: Owner-manager - June } 14,2014 \text { ) }\end{array}$ \\
\hline $2^{\text {nd }}$ LEVEL OF IT-ENABLED TRANSFORMATION \\
\hline Practices about collaboration (capabilities) - HR and relational capabilities \\
\hline $\begin{array}{l}\text { Survey firms use our services when they have questions concerning the programming of these tools.. [...] Moreover, we are now } \\
\text { directly referred by the R\&D people working for the developer (ISPartner) who tell us how they are impressed with what we managed } \\
\text { to do with their own tools. [...] We must take advantage of this network and we must also be able to give support to others who are } \\
\text { on the same technological platform as us. (source: IT manager - December } 6,2013 \text { ) }\end{array}$ \\
\hline Processes about knowledge (learning) \\
\hline $\begin{array}{l}\text { [You can see it as a community of practices, yes] because it is not a mainstream applicat } \\
\text { there are few people who have the skills [to use] those applications or adapt them to } \\
\text { December } 6,2013 \text { ) }\end{array}$ \\
\hline
\end{tabular}

January 2016, this partner, with whom CallCenter has been doing business since its beginnings, had offices in North America, Europe, and Australia and sells worldwide to over 500 companies. In this context and because of its size and language service differentiation, CallCenter has always been considered as "a small player in the major leagues". However, far from being a disadvantage, these characteristics rather constitute a competitive advantage for the company in its business niche, as mentioned by CallCenter's owner: "What makes our reputation is the speed with which we react, our ability to implement a project quickly. [...] At the same time, we must not forget that we work with partners that are enormous. We are talking about research companies that have 5000 or 7000 employees. The respective missions that underlie the exchanges and collaboration processes between these two long-time partners are the following: "Our mission is to improve our clients' performance through the quality of our [services and] initiatives" (CallCenter). "[...] We work more like a data collection partner than simply a survey tool provider" (extract from ISPartner's web site).

CallCenter's owner reports that, since 2012, there has been more and more collaboration with ISPartner to develop specific services such as automated delivery confirmation as well as self-completion surveys and customer service automated messages, including mobile interfaces, all based on shared IT artifacts. This increased collaboration between the two partners for renewing existing services and developing new ones illustrates a context in which the partners' vision and IT artifacts constitute "balanced structures" (Kauppila, 2010), "collaborative arrangements" (Knoben \& Oerlemans, 2006) as well "IT integration" (Raymond et al., 2013), even though these organizations are two formally separate business firms. Nevertheless, due to the increasing outsourced activities within their industry (Chou, 2011; Jack et al., 2006), both firms were facing the need of a better orchestration of their 


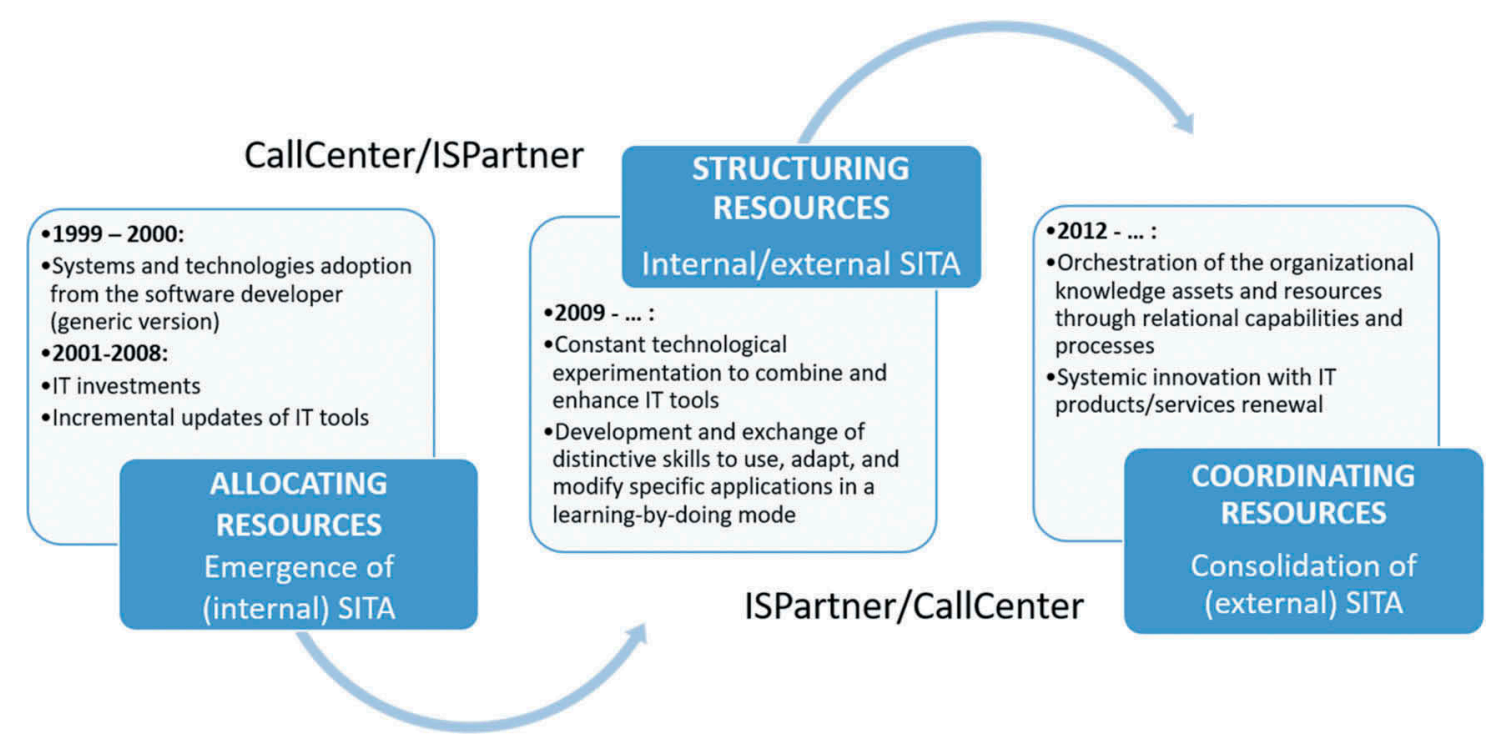

Figure 2. Mapping of CallCenter's SITA process.

organizational knowledge assets and resources related to their shared use of specialized IT artifacts.

Concerning the managerial challenges of such a situation, this increased collaboration between CallCenter and ISPartner also underscored the needs for more "dynamic and real-time alignment processes" (Tarafdar \& Qrunfleh, 2009, p. 339). In this context, our retrospective study covered a twelve-year period (1999-2012) during which CallCenter aligned itself with its main business partner at multiple levels. First, in terms of shared vision and IT artifacts and, second, in terms of shared IT knowledge and practices. These results are consistent with the view that "different structures are required for exploitation and exploration" (O'Reilly \& Tushman, 2013, p. 325). This also means that when collaborating, CallCenter and ISPartner are able to foster systemic innovation that benefits an entire industry (Helfat et al., 2007). For instance, ISPartner took advantage of shared IT knowledge to develop new products and consolidate its advantage of being the most sought-after IVR system in a growing market. Indeed, according to CallCenter's owner-manager, "they (ISPartner) might treat us as a simple client, but they go beyond by referring us to their international clients. Often, they will even invite us to participate in [joint or completely outsourced] mandates".

\section{CallCenter's IT assets orchestration mechanisms}

We initially observed that the relationship between CallCenter and ISPartner was specifically based on three interrelated and recurrent orchestration mechanisms, namely the allocation, structuration and coordination of IT resources. Moreover, because these resources are mainly intangible in the contemporary business context, effective management of the SITA process is a way to link more tangible resources (vision and IT artifacts) with more intangible ones (IT knowledge and practices). Thus, analyzing through an integrative theoretical lens how CallCenter develops and manages its SITA process allowed us to better understand how IT asset orchestration mechanisms transformed the firm's initial IT assets into more complex IT resources and practices (Maritan \& Peteraf, 2011). In other words, combining capability, learning and ambidexterity perspectives of SITA for IT-enabled transformation highlights how a productive use of IT evolves toward users, teams and organizations (Feurer et al., 2000; Ragowsky et al., 2012).

\section{Mechanism 1 - allocating IT resources}

Initially motivated by competitive considerations and the willingness to use the most widespread systems and technologies in the market occupied, the relationship between CallCenter and its main partner, ISPartner, was first established on purely technical grounds. Until 2008, CallCenter maintained an "activitydomain-based" relationship with its systems supplier (Albers, Wohlgezogen, \& Zajac, 2016), within which it adopted, abandoned or modified its technology infrastructure at the whim of new versions and features offered by ISPartner, whose products offering was the same to all of its customers. Nevertheless, a growing use of IT and the emergence of specialized software applications as well as the need for improved management 
of organizational assets and capabilities was experienced by within CallCenter's business environment. Based on specific operational requirements in this field of activity, the IT resources allocation mechanism was thus affected by greater investments in IT and the implementation of security and control devices. Owning $100 \%$ of its technological infrastructure, CallCenter's hardware and software resources were updated when necessary, not on the basis of a planned renewal schedule. For the company's ownermanager, such IT resources as well as the knowledge that came from their increased use had enabled the firm "to detect opportunities and unaddressed needs." For CallCenter's IT manager, this situation was summarized as follows: "Technologically speaking, I think, we surpass competitors, even the biggest ones." This confirmed that an adequate resources allocation mechanism was a mean to overcome organizational inertia in a context of rapid change and increased competition (Besson \& Rowe, 2012; Gilbert, 2005).

\section{Mechanism 2 - structuring IT resources}

Starting with usual IT artifacts, CallCenter's initial SITA process really began in 2010. Founded on a more collaborative perspective with regard to $R \& D$ and IT development, this change was needed when web survey applications started to become the preferred choice compared to phone survey services. As mentioned by CallCenter's owner: "This is not an application for the general public. [...] It is specific to our services. Few people have skills to use, adapt, and modify these applications to specific situations [that arise in our business environment]. [...] To successfully integrate all of these operations, be it functional and ... efficient, and therefore the client is satisfied, will probably bring us into another league." CallCenter engaged in constant technological experimentation to combine and enhance its IT tools after 2011, thus indicating the presence of an IT structuring resources mechanism within its SITA management process. Moreover, the IT personnel transformed existing the IT resources in a creative learning-by-doing mode through knowledge sourcing and knowledge management and sourcing activities (Ribeiro-Soriano \& Urbano, 2009; Vrontis et al., 2017): "With the new software, there is an improved version for the automated calls, which I use in part. But I also use the older version, because with the new one, we cannot do everything. Often, I make hybrid versions with both" (IT manager).

Illustrating how CallCenter and ISPartner regularly combined their various resources to act beyond a simple customer-supplier exchange (Gulati,
Puranam, \& Tushman, 2012; Loebbecke et al., 2016), CallCenter's owner mentioned: "There is nothing sexy about the IVR (interactive voice response). It has been around for a long time. It's just about bringing it up to date and applying it creatively [with constant experimentation and collaboration with its developer]." The IT manager also mentioned about CallCenter's longterm use of ISPartner's systems: "We don't need more employees to do all this because we now have the technology to do what we need in an automated way."

\section{Mechanism 3 - coordinating IT resources}

In a business context characterized by an increased complexity and a growing use of IT (Besson \& Rowe, 2012; Reynolds \& Yetton, 2015), CallCenter's relationship with ISPartner is more than simply acquiring, installing and updating existing software tools (Feurer et al., 2000). As a result of the previous allocating and structuring mechanisms, the IVR services now offered by CallCenter are based on the existing shared IT artifacts, i.e. the most widely-used software platforms and workflow solutions in CallCenter's business sector, and on large volumes of data, automated and custommade application solutions. To support this shift, the technological infrastructure was entirely renewed in 2009.

As emphasized by Ragowsky et al. (2012), this kind of IT investment decision reveals a form of organizational readiness that "emphasizes the ability of non-IT people [...] to understand IT (its capabilities and constraints), communicate with the IT people, specify, ask for, deploy, and use information technology productively and responsibly within a business context" (p. 148). Moreover, notwithstanding the importance of the technological infrastructure in such a context, a productive use of IT assets also relies on an extensive knowledge-sharing across the organization as well as with its clients and other partners. In this regard, the fact that ISPartner now directly refers to CallCenter for specific mandates underscores the IT knowledge and capabilities that are emerging from this SME experimenting with the IT artifacts developed by its partner. Both partners thus need not only effective communication mechanisms between them, but also mutual exchanges that are founded upon "aligned" decisionmaking processes of their respective IT functions and of their other functions as well (Tarafdar \& Qrunfleh, 2009). CallCenter's SITA process thus provides this firm with more coordination efficacy through formal and informal structures (Williams \& Karahanna, 2013), and through trade-offs agreed to between itself and ISPartner (Brown, 1999). 
In sum, the shift toward more sophisticated services such as IVR represented a milestone in the management of CallCenter's alignment with ISPartner. Following years of IT resource development and exchanges, CallCenter's owner concludes: "There are no silos of expertise; we do not have that mind-set ... [...] Because we are on the same technological platform (than ISPartner), it is very easy to exchange projects. There are a lot of outsourcing activities that are done in our sector and this is much easier when you are on the same platform. [In this regard] it is now very easy to be able to exchange projects. There is total continuity and total control of our projects. [...] In terms of the purely technical infrastructure, we have everything we need. It's really at the level of the organizational structure that things happen [now]." In an illustration of how a small firm offering IT-based services had successfully managed its SITA process (Chang et al., 2011), CallCenter's revenues approached 3 million dollars in 2012, of which $70 \%$ came from outside its home province (Quebec).

\section{CallCenter's $2^{\text {nd }}$ level of IT-enabled transformation: external SITA}

Because of the long-standing business agreements dating back to CallCenter's inception, the shift from an educational training context to private commercial research and marketing services (i.e. opinion polls, satisfaction measurement surveys, market studies) through telephonic and web platforms has been completed in 2008. More specifically, and beginning in 2010, there was an increasing demand for such high-value services by companies in different sectors, such as banking, insurances, transportation, and retailing. Since then and following major competitive and technological changes in its sector of activity, the firm opened up its expertise in the design and development of marketing analysis tools through tailor-made automated solutions.

This important shift was made by CallCenter through an IVR platform to allow fully automated communications, such as the confirmation of a delivery or the largescale diffusion of information to customers by organizations such as furniture stores or delivery service companies. In an era of digital transformation, these services possess a greater strategic value for many firms because of the IT knowledge integration as well as the sophisticated IT architecture required (Ragowsky et al., 2012). This situation also means that, through appropriate managerial actions and adequate governance mechanisms (Tarafdar \& Qrunfleh, 2009), human agents are able to cooperate and choose the best course of action to deploy interorganizational IT artifacts as well as to improve value creation through IT-enabled cross-organizational business processes (Diirr \& Cappelli, 2018; Ibrahim, Ribbers, \& Bettonvil, 2012).

All in all, CallCenter did what was needed to survive and compete in a rapidly changing business context (El Sawy \& Pavlou, 2008). As well, this firm reorganized its activities, including its managerial, technological structures, and most importantly its relational structures (Dyer \& Kale, 2007; Dyer \& Singh, 1998). As mentioned by CallCenter's owner-manager: "There is now a lot of outsourcing going on in our field and it's made much easier when you're on the same platform. [...] Moreover, we are now directly referred to by our software developer's (ISPartner) R\&D people who tell us how they are impressed with what we managed to do with their tools".

At the end of the period studied, through effective IT resource allocating, structuring and coordinating mechanisms, CallCenter was able to mobilize the same capabilities to develop other partnerships over the years in addition to the main one with ISPartner. In this regard, 2010 was a turning point for the organization. More specifically, CallCenter started to place greater emphasis on making better use of the specialized IT resources and capabilities that have been developed since 1999. In particular, these partnerships were initiated over time with the intention to develop and complement IT resources and competencies with regards to CallCenter's IT infrastructure, networks, web development and IT security.

For the owner-manager, despite "less control" of certain aspects of the firm's activities, SITA processes are the path to the renewal and consolidation of the company in its specialized services niche within a business-to-business ecosystem (Kelly \& Scott, 2012; Vrontis et al., 2017). Without the prescribed sequence dictated by a typical life-cycle approach (Helfat \& Peteraf, 2003; Van de Ven \& Poole, 1995), CallCenter was then able to create as well as to maintain business partnerships that were "aligned" (Feurer et al., 2000; Reynolds \& Yetton, 2015). As illustrated by CallCenter's owner-manager: "Our customers have become increasingly demanding, and this has required us to make critical decisions and take important actions in order to ensure business continuity." In other words, these specialized IT-enabled partnerships initiated by the firm were based on the exploration of new IT resources and competencies that were supported and reinforced by the exploitation of the existing ones. 


\section{Discussion}

In the light of the preceding results, and recalling both the gap in the literature and the theory-practice gap that motivated our study of the SITA process, this exploratory case illustrates how a small firm was able to mitigate change in its business environment by developing co-specialized and complementary IT assets and capabilities through a set of mechanisms that allow to jointly achieve IT-business value (Prasad \& Green, 2016), including other benefits such as service innovation and renewal (Chang et al., 2011; Vrontis et al., 2017). In this regard, the data analysis suggests that in order to ensure the success of SITA for IT-enabled transformation, allocating and structuring IT resource mechanisms must go beyond an R\&D alliance which is based simply on the complementarity of IT assets (Albers et al., 2016; Barringer \& Harrison, 2000). In the words of CallCenter's owner-manager, the situation is summarized as: "Everything is there! It's a case of $100 \%$ relational capability", which is also coherent with the leadership issue related to the capability perspective of IT-enabled transformation (Besson \& Rowe, 2012; Dyer \& Kale, 2007). Based on the above argumentation, we formulate two propositions for future research:

- Proposition 1: The appropriate allocation of IT resources will improve the performance of collaboration within a SITA process by allowing the firm to internally and externally share more IT competencies and knowledge.

- Proposition 2: The appropriate structuration of IT resources will improve the performance of collaboration within a SITA process by allowing the firm to organize internal and external exchanges around activities of higher IT-business value.

Representing milestones in the strategic development and organizational performance of the firm that has been observed in this case study, IT asset orchestration mechanisms cumulated over the years between CallCenter and ISPartner. These mechanisms were supported by multilevel social structures, founded on the sharing of IT artifacts, an IT vision as well as IT competencies and knowledge. In coherence with an integrative approach, both firms now emphasize maintaining their successful relationship through the allocation, the structuration and the coordination of their respective IT resources and competencies (Gilbert, 2005; Sirmon et al., 2011). In this regard, our findings revealed that CallCenter not only developed specialized IT resources (Prasad \& Green, 2016) based on shared
IT competencies and knowledge (Loebbecke et al., 2016; Maritan \& Brush, 2003), but also evolved from managerial activities to entrepreneurial opportunities (Alvarez \& Barney, 2007; Ibrahim et al., 2012). CallCenter's owner describes the situation as follows: "We realize that there are many unmet needs if a company like ours is able to offer a solid process automation solution using good old technology, but by applying it in a proactive way. [...] In fact, we are not renewing the service itself, but the way we offer it." Based on the above argumentation, we propose a third research proposition:

- Proposition 3: The appropriate coordination IT resources will improve the performance of collaboration within a SITA process for IT-enabled transformation by allowing the firm to transform internal managerial activities into external entrepreneurial opportunities.

In answer to our first research question, we proposed a framework and a plausible identification of the asset orchestration mechanisms that allow to better understand the emergence as well as the management of a SITA process for IT-enabled transformation. In answer to our second question, our findings suggest that the three IT asset orchestration mechanisms identified are interrelated, and that they interact with other organizational and IT-related processes and structures. In doing so, these mechanisms mutually reinforced through the deployment of various resources that are acquired (allocating), developed (structuring) and eventually shared (coordinating) by means of IT capabilities and knowledge (Ibrahim et al., 2012).

This view of the SITA process is coherent with a "recursive" approach as well as a "dialectic" mode of change wherein the asset orchestration mechanisms represent a more concrete translation of the thesis, antithesis and synthesis sequence referred to by Van de Ven and Poole (1995, p. 517) when a balance of power occurs between opposing entities in a complex process such as SITA. Compared to the recursive approach proposed here, prior research has rather underscored an evolutionary mode of change through mechanisms such as variation, selection, and retention, that is, "linear" mechanisms founded on a recurrent and cumulative progression of various elements in a prescribed sequence (Van de Ven \& Poole, 1995). In this line of thought, our study reinforces the "necessity to move from a single or dyadic relationship towards multi-level research to understand the nonlinear interactions between alignment dimensions that might be operating simultaneously over time" (Benbya et al., 2019, p. 4). 
From a practical point of view and following our observations of how CallCenter allocated, structured, and coordinated its activities with ISPartner over time, our results underscore that structures do not always need a formal arrangement to provide performance (Ribeiro-Soriano \& Urbano, 2009; Vrontis et al., 2017), business opportunities (Ibrahim et al., 2012), desired outcomes (Brown, 1999), or indirect benefits such as IT-enabled service innovation and renewal (Chang et al., 2011), and especially in SMEs (Levy et al., 2003). From such a perspective, our attention was given to specific IT asset orchestration mechanisms, that is, to "recurring patterns that underlie and guide surface, observable events and actions" (Heracleous \& Barrett, 2001, p. 758). This includes the challenges related to collaboration in general, as well as the actions that trigger and affect contextualized collaborative efforts within the SITA process.

In summary, the preceding findings illustrate that the management of a SITA process is based on much more than geographical or technological proximity (Croteau et al., 2008; Davis \& Marquis, 2005; Ragowsky et al., 2012). The case data suggest that the CallCenter's growing collaboration with ISPartner was based on "organizational proximity" (Knoben \& Oerlemans, 2006), and could not emerge without prior efforts to reach an internally-shared vision and business understanding of the quality of products and services that the two partners wanted to offer. As indicated by CallCenter's owner-manager: "We must take advantage of this network and we must also be able to give support to others who are on the same technological platform as us [...] In addition to technical support from the company that develops and sells these systems, we often offer support on programming problems to polling firms." Our analysis of the case data thus suggests that the interactions of CallCenter's structures are founded on the development of a set of IT asset orchestration mechanisms that closely relate to different action and decision levels in the firm (Alvarez \& Barney, 2007; Tarafdar \& Qrunfleh, 2009).

Finally, given the preceding observations, our case study revealed different levels of IT-enabled transformation, through the SITA process. In other words, it revealed "a set of routines based on product technologies, process technologies, or broader business innovations as well as managerial activities" (Maritan \& Brush, 2003, pp. 945-946), and within which different levels of interactions and managerial actions also occur (O'Reilly \& Tushman, 2013). In this view, any organizational change will also affect these patterns (i.e. knowledge and practices) and principles of interaction by imposing new and different set of rules and practices
(Gersick, 1991). Based on the above arguments, we suggest that IT-enabled transformation as well as innovation will emerge from a SITA process by a continuous adjustment between these internal and external structures, and through IT resource allocating, structuring and coordinating mechanisms.

\section{Contributions to theory and practice}

In attempting to fill both the gap in the literature and the theory-practice gap that motivated this study of the SITA process, we make a number of contributions to the theory and practice of IT alignment. When compared to past studies on strategic IT alignment that have used a number of theoretical lenses (Barringer \& Harrison, 2000; Chan \& Reich, 2007; Croteau et al., 2008), the use of IT asset orchestration mechanisms provide a plausible explanation of the SITA process that goes beyond the mere description of resources, transactions and structures (Helfat et al., 2007; Robey et al., 2008). Further insight into the social dimension of the complex phenomenon of IT alignment is thus provided, as the case study's findings allow us to conclude that the SITA process constitutes a crucial way for the firm to develop its key capabilities (Holmqvist, 2004; Lavie \& Rosenkopf, 2006), and especially for SMEs (Levy et al., 2003; Raymond et al., 2013). These findings also allow us to better understand how distinct organizational capabilities arise from specific IT managerial activities (Tarafdar \& Qrunfleh, 2009), and concrete actions (Feurer et al., 2000).

Theoretically speaking, the combination of the organizational capabilities, learning and ambidexterity perspectives for IT-enabled transformation, through the IT asset orchestration concept stemming from the extended-RBV approach (Helfat et al., 2007), is appropriate for the study of the SITA process for many reasons. First, because the asset orchestration lens "consists of two primary dimensions - search/selection and configuration/deployment" (Sirmon et al., 2011, p. 1391) which directly concern capability-building potential of an organization (Maritan \& Peteraf, 2011). Second, such an approach recognizes the social context of organizational learning when "selection among forms, routines, or practices is essential to survival, but so also is the generation of new alternative practices, particularly in a changing environment" (March, 1991, p. 72). Third, because the ambidexterity concept "says that managers are making choices and trade-offs among competing objectives, and when they do their job well they override the organization's tendency to go down the path of least resistance" (Birkinshaw \& Gupta, 2013, p. 293). However, this situation invites us to question not only on a fundamental subject of research in the field of IS (Tanriverdi et al., 2010), but above all on a process that 
still poses many challenges for researchers and practitioners alike, that is, strategic IT alignment (Reynolds \& Yetton, 2015).

Overall, our study provides several contributions to theory in the IS domain as well as it shows promising avenues for research on the role of the three orchestration mechanisms that are required to organize the IT resources necessary to create and implement interfirm processes, systems and practices (Helfat et al., 2007; Sirmon et al., 2011). While rich insights have been obtained, the data from this single-case study only provides preliminary support for our theorization of the management of a SITA process (Miles et al., 2014; Yin, 2009). Thus, despite its potential to provide a foundation for the further empirical analyses as well as for a deeper understanding of the key challenges relating to the development, implementation and success of SITA process for IT-enabled transformation, in-depth multiple case studies and survey studies must be conducted in the future to determine the extent of our analytical framework's explanatory power and to add to it.

Our specific concern with the practical usefulness of this research also encouraged us to engage in a theorizing effort that emphasizes mechanism-based theorizing (Davis \& Marquis, 2005). In doing so, our study provides practicebased guidelines for managerial actions (Tarafdar \& Qrunfleh, 2009), and guidance in particular to service SMEs in the strategic adaptation to partnership-based IT projects that is or will be required of them (Birkinshaw \& Gupta, 2013).

Another practical implication of our increased knowledge of the SITA process lies in a better understanding of how, in the digital era, the orchestration of IT assets impacts other IT-related processes such as strategic IT alignment and IT governance. This contribution was made by unveiling the social relationships as well as the shared IT competencies and knowledge that emerged within this process and affected the firm's decision-making with regard to the its use, management and governance of IT (Diirr \& Cappelli, 2018; Tarafdar \& Qrunfleh, 2009).

Given the case study method employed and the theoretical choices made, it is obvious that further research is needed to provide more solid grounding to our study's findings and conclusions, as well as to test the three research propositions that emanate from this study. One should thus confirm - and add to - the 'rich insights' obtained through this research and provide greater evidence of its 'transferability' to other settings (Poba-Nzaou \& Raymond, 2013). And one might do so by doing multiple case studies of the SITA process in different organizational, interorganizational and industry contexts, as well as by examining this process through appropriate theoretical lenses other than asset orchestration, such as organizational learning
(Ragowsky et al., 2012) and ambidexterity (Gregory, Keil, Muntermann, \& Mähring, 2015).

\section{Conclusion}

Through an interpretive case study, we assessed the realization as well as the management of a social IT alignment process in the context of a Canadian SME specialized in web surveys and interactive voice response services. In so doing, we answered the call for a better comprehension of a complex phenomenon, namely the strategic IT alignment and the IT-enabled transformation of SMEs in a global, knowledge-based economy, and through the social dimension of IT alignment in particular (Benbya et al., 2019; Markus et al., 2006; Robey et al., 2008). More specifically, we examined how the firm's alignment process, structures, and managerial activities aligned and integrated with those of its main business partner through the theoretical lens of asset orchestration mechanisms. The data analysis suggests that internal as well as external social structures are connected by three IT asset orchestration mechanisms (allocation, structuration, and coordination), that enable a better utilization of the firm's IT resources and competencies.

\section{Notes on contributors}

Claudia Pelletier, DBA, is Assistant Professor of information systems and a researcher at the Institute for Research on SMEs at the Université du Québec à Trois-Rivières. Her work has been published in journals such as Journal of Small Business and Enterprise Development and Revue Internationale $P M E$, as well as in international conference proceedings such as HICSS and AMCIS. Professor Pelletier's current research interests focus on the IT strategic alignment process and IT-enabled organizational transformation, and on the challenges of digital transformation in the business ecosystem, including issues surrounding Industry 4.0 in the particular context of small and medium-sized enterprises (SMEs).

Anne-Marie Croteau, PhD, CDir, is Dean of the John Molson School of Business at Concordia University in Montreal, Canada. She is Professor of strategic management of information technology. Her work has been published in journals such as the Journal of Strategic Information Systems, Journal of Information Technology, IEEE Transactions on Engineering Management and Computers in Human Behavior, as well as in international proceedings such as ICIS and HICSS. Professor Croteau's current research studies the reality of gigworkers through the lens of the organizational support theory.

Louis Raymond, PhD, is Emeritus Professor of information systems and a researcher at the Institute for Research on SMEs at the Université du Québec à Trois-Rivières. His work has been published in journals such as the MIS 
Quarterly, Entrepreneurship Theory and Practice, Information Systems Journal, Journal of Management Information Systems, Project Management Journal, European Journal of Information Systems and International Journal of Medical Informatics, as well as in international proceedings such as ICIS and HICSS. Professor Raymond's current research involves the strategic management of information technology and its performance impacts in the small business context and in the healthcare sector.

Dragos Vieru, PhD, is Full Professor at TELUQ University in Montreal and researcher at the Research Group in Information Systems of HEC Montreal. His research interests are in the areas of IT-enabled organizational change, global IT sourcing, and ethics in IT. His work has been published in journals such as the Journal of Knowledge Management, the International Journal of Information Management and the Journal of Information Technology Teaching Cases, as well as in international conference proceedings such as ICIS and HICSS. Professor Vieru's current research involves organizational ambidexterity and its impact on IT innovation in the IT services industry.

\section{ORCID}

Louis Raymond (D) http://orcid.org/0000-0003-1631-8171

\section{References}

Albers, S., Wohlgezogen, F., \& Zajac, E. J. (2016). Strategic alliance structures: An organization design perspective. Journal of Management, 42(3), 582-614. doi:10.1177/ 0149206313488209

Alvarez, S. A., \& Barney, J. B. (2007). Discovery and creation: Alternative theories of entrepreneurial action. Strategic Entrepreneurship Journal, 1(1-2), 11-26. doi:10.1002/sej.4

Aral, S., \& Weil, P. (2007). IT assets, organizational capabilities, and firm performance: How resource allocations and organizational differences explain performance variation. Organization Science, 18(5), 763-780. doi:10.1287/orsc.1070.0306

Barney, J. B., Ketchen, D. J., \& Wright, M. (2011). The future of resource-based theory. Journal of Management, 37(5), 1299-1315. doi:10.1177/0149206310391805

Barringer, B. R., \& Harrison, J. S. (2000). Walking a tightrope: Creating value through interorganizational relationships. Journal of Management, 26(3), 367-403. doi:10.1177/014920630002600302

Benbya, H., Leidner, D. E., \& Preston, D. (2019). MISQ research curation on information systems alignment. MIS Quarterly. Retrieved from https://static1.squarespace.com/ static/ 5887 a 660 b 3 db 2 b 05 bd 09 cf $36 / t / 5$ deffae 53 d673974a3921cde/1576008422409/MISQ+curation+on+IS +Alignment-FINAL.pdf

Besson, P., \& Rowe, F. (2012). Strategizing information systems-enabled organizational transformation: A transdisciplinary review and new directions. Journal of Strategic Information Systems, 21(2), 103-124. doi:10.1016/j.jsis.2012.05.001

Birkinshaw, J., \& Gupta, K. (2013). Clarifying the distinctive contribution of ambidexterity to the field of organization studies. Academy of Management Perspectives, 27(4), 287-298. doi:10.5465/amp.2012.0167
Brown, C. V. (1999). Horizontal mechanisms under differing is organization contexts. MIS Quarterly, 23(3), 421-454. doi: $10.2307 / 249470$

Cao, L., Mohan, K., Ramesh, B., \& Sarkar, S. (2014). Evolution of governance: Achieving ambidexterity in IT outsourcing. Journal of Management Information Systems, 30(3), 115-140. doi:10.2753/MIS0742-1222300305

Cegarra-Navarro, J. G., \& Dewhurst, F. (2007). Linking organizational learning and customer capital through an ambidexterity context: An empirical investigation in SMEs. International Journal of Human Resource Management, 18(10), 1720-1735. doi:10.1080/09585190701570882

Chan, Y., \& Reich, B. (2007). IT alignment: What have we learned? Journal of Information Technology, 22, 297-315. doi:10.1057/palgrave.jit.2000109

Chang, -Y.-Y., Hughes, M., \& Hotho, S. (2011). Internal and external antecedents of SMEs' innovation ambidexterity outcomes. Management Decision, 49(10), 1658-1676. doi:10.1108/00251741111183816

Chi, M., Zhao, J., George, J. F., Li, Y., \& Zhai, S. (2017). The influence of relational strategies on relational performance: The moderation effect of information technology ambidexterity. International Journal of Information Management, 37, 43-53. doi:10.1016/j. ijinfomgt.2016.11.007

Chou, T. C. (2011). Exploring call center-enabled organizational mechanisms associated with combinative capabilities. Management Decision, 49(6), 841-859. doi:10.1108/ 00251741111143577

Croteau, A.-M., Léger, P.-M., \& Cassivi, L. (2008). The role of life cycle concepts in the assessment of interorganizational alignment. Industrial Management \& Data Systems, 108(2), 145-161. doi:10.1108/02635570810847545

Davis, G. F., \& Marquis, C. (2005). Prospects for organization theory in the early twenty-first century: Institutional fields and mechanisms. Organization Science, 16(4), 332-343. doi:10.1287/orsc.1050.0137

Diirr, B., \& Cappelli, C. (2018). A systematic literature review to understand cross-organizational relationship management and collaboration. Proceedings of the 51st Hawaii International Conference on System Sciences (pp. 145-154). Kailua-Kona, Hawaii. doi:10.1007/s11748-017-0860-3

Dyer, J. H., \& Kale, P. (2007). Relational Capabilities: Drivers and Implications. In C. E. Helfat (Ed.), Dynamic capabilities understanding strategic change in organizations (pp. 65-79). Oxford, UK: Blackwell Publishing.

Dyer, J. H., \& Singh, H. (1998). The relational view: Cooperative strategy and sources of interorganizational competitive advantage. Academy of Management Review, 23(4), 660-679. doi:10.5465/amr.1998.1255632

Eisenhardt, K. M. (1989). Building theories from case study research. Academy of Management Review, 14, 532-550. doi:10.5465/amr.1989.4308385

Eisenhardt, K. M., \& Graebner, M. E. (2007). Theory building from cases: Opportunities and challenges. Academy of Management Journal, 50(1), 25-32. doi:10.5465/ amj.2007.24160888

El Sawy, O. A., \& Pavlou, P. A. (2008). IT-enabled business capabilities for turbulent environments. MIS Quarterly Executive, 7(3), 139-150.

Feurer, R., Chaharbaghi, K., Weber, M., \& Wargin, J. (2000). Aligning strategies, processes, and IT: A case study. 
Information Systems Management, 17(1), 23-34. doi:10.1201/1078/43190.17.1.20000101/31211.4

Gersick, C. J. (1991). Revolutionary change theories: A multilevel exploration of the punctuated equilibrium paradigm. Academy of Management Review, 16(1), 10-36. doi:10.5465/amr.1991.4278988

Gibson, C. B., \& Birkinshaw, J. (2004). The antecedents, consequences, and mediating role of organizational ambidexterity. Academy of Management Journal, 47(2), 209-226.

Gilbert, C. G. (2005). Unbundling the structure of inertia: Resource versus routine rigidity. Academy of Management Journal, 48(5), 741-763. doi:10.5465/amj.2005.18803920

Gregory, R. W., Keil, M., Muntermann, J., \& Mähring, M. (2015). Paradoxes and the nature of ambidexterity in IT transformation programs. Information Systems Research, 26(1), 57-80. doi:10.1287/isre.2014.0554

Gulati, R., Puranam, P., \& Tushman, M. (2012). Metaorganization design: Rethinking design in interorganizational and community contexts. Strategic Management Journal, 33(6), 571-586. doi:10.1002/smj.1975

Helfat, C. E., Finkelstein, S., Mitchell, W., Peteraf, M. A., Singh, H., Teece, D. J., \& Winter, S. G. (2007). Dynamic capabilities. Understanding strategic change in organizations. Oxford, UK: Blackwell Publishing.

Helfat, C. E., \& Peteraf, M. A. (2003). The dynamic resource-based view: Capability lifecycles. Strategic Management Journal, 24 (10), 997-1010. doi:10.1002/()1097-0266

Henderson, J. C., \& Venkatraman, H. (1993). Strategic alignment: Leveraging information technology for transforming organizations. IBM Systems Journal, 32(1), 4-16. doi:10.1147/sj.382.0472

Heracleous, L., \& Barrett, M. (2001). Organizational change as discourse: Communicative actions and deep structures in the context of information technology implementation. Academy of Management Journal, 44(4), 755-778.

Holmqvist, M. (2004). Experiential learning processes of exploitation and exploration within and between organizations: An empirical study of product development. Organization Science, 15(1), 70-81. doi:10.1287/orsc.1030.0056

Ibrahim, M., Ribbers, P. M., \& Bettonvil, B. (2012). Humanknowledge resources and interorganisational systems. Information Systems Journal, 22(2), 129-149. doi:10.1111/ isj.2012.22.issue-2

Im, G., \& Rai, A. (2014). IT-enabled coordination for ambidextrous interorganizational relationships. Information Systems Research, 25(1), 72-92. doi:10.1287/isre.2013.0496

Jack, E. P., Bedics, T. A., \& McCary, C. E. (2006). Operational challenges in the call center industry: A case study and resource-based framework. Managing Service Quality, 16 (5), 477-500. doi:10.1108/09604520610686142

Jansen, J. J., Tempelaar, M. P., Van den Bosch, F. A., \& Volberda, H. W. (2009). Structural differentiation and ambidexterity: The mediating role of integration mechanisms. Organization Science, 20(4), 797-811. doi:10.1287/orsc. 1080.0415

Jin, L., \& Robey, D. (2008). Bridging social and technical interfaces in organizations: An interpretive analysis of time-space distanciation. Information \& Organization, 18 (3), 177-204. doi:10.1016/j.infoandorg.2007.12.001

Kauppila, O.-P. (2010). Creating Ambidexterity by Integrating and Balancing Structurally Separate Interorganizational
Partnerships. Strategic Organization, 8(4), 283-312. doi:10.1177/1476127010387409

Kelly, S., \& Scott, D. (2012). Relationship benefits: Conceptualization and measurement in a business-tobusiness environment. International Small Business Journal, 30(3), 310-339. doi:10.1177/0266242610381297

Klein, H. K., \& Myers, M. D. (1999). A set of principles for conducting and evaluating interpretive field studies in information systems. MIS Quarterly, 23(1), 67-94. doi: $10.2307 / 249410$

Klein, K. J., Dansereau, F., \& Hall, R. J. (1994). Levels issues in theory development, data collection, and analysis. Academy of Management Review, 19(2), 195-229. doi:10.5465/amr.1994.9410210745

Knoben, J., \& Oerlemans, L. A. G. (2006). Proximity and inter-organizational collaboration: A literature review. International Journal of Management Reviews, 8(2), 71-89. doi:10.1111/ijmr.2006.8.issue-2

Langley, A., Smallman, C., Tsoukas, H., \& Van de Ven, A. H. (2013). Process Studies of Change in Organization and Management: Unveiling Temporality, Activity, and Flow. Academy of Management Journal, 56(1), 1-13. doi:10.5465/ amj.2013.4001

Lavie, D., \& Rosenkopf, L. (2006). Balancing exploration and exploitation in alliance formation. Academy of Management Journal, 49(4), 797-818. doi:10.5465/ amj.2006.22083085

Levina, N. (2005). Collaborating on multiparty information systems development projects: A collective reflection-inaction view. Information Systems Research, 16(2), 109-130. doi:10.1287/isre.1050.0055

Levy, M., Loebbecke, C., \& Powell, P. (2003). SMEs, co-opetition and knowledge sharing: The role of information systems. European Journal of Information Systems, 12 (1), 3-17. doi:10.1057/palgrave.ejis.3000439

Loebbecke, C., van Fenema, P. C., \& Powell, P. (2016). Managing inter-organizational knowledge sharing. Journal of Strategic Information Systems, 25(1), 4-14. doi:10.1016/j.jsis.2015.12.002

Majchrzak, A., Jarvenpaa, S. L., \& Bagherzadeh, M. (2015). A review of interorganizational collaboration dynamics. Journal of Management, 41(5), 1338-1360. doi:10.1177/ 0149206314563399

March, J. G. (1991). Exploration and exploitation in organizational learning. Organization Science, 2(1), 71-87. doi:10.1287/ orsc.2.1.71

Maritan, C. A., \& Brush, T. H. (2003). Heterogeneity and transferring practices: Implementing flow manufacturing in multiple plants. Strategic Management Journal, 24(10), 945-959. doi:10.1002/()1097-0266

Maritan, C. A., \& Peteraf, M. A. (2011). Building a Bridge between Resource Acquisition and Resource Accumulation. Journal of Management, 37(5), 1374-1389. doi:10.1177/0149206310387675

Markus, M. L., Steinfield, C. W., Wigand, R. T., \& Minton, G. (2006). Industry-wide information systems standardization as collective action: The case of the U.S. Residential mortgage industry. MIS Quarterly, 30, 439-465. doi:10.2307/25148768

Miles, M. B., Huberman, A., \& Saldaña, J. (2014). Qualitative data analysis: A methods sourcebook (3rd ed.). Thousand Oaks, CA: Sage Publications. 
Myers, M. D., \& Newman, M. (2007). The qualitative interview in IS research: Examining the craft. Information and Organization, 17(1), 2-26. doi:10.1016/j.infoandorg.2006.11.001

O’Reilly, C. A., \& Tushman, M. L. (2013). Organizational ambidexterity: Past, present, and future. Academy of Management Perspectives, 27(4), 324-338. doi:10.5465/ amp.2013.0025

Pentland, B. T. (1999). Building process theory with narrative: From description to explanation. Academy of Management Review, 24(4), 711-724. doi:10.5465/ amr.1999.2553249

Pentland, B. T., \& Feldman, M. S. (2005). Organizational routines as a unit of analysis. Industrial and Corporate Change, 14(5), 793-815. doi:10.1093/icc/dth070

Piccoli, G., \& Ives, B. (2005). IT-dependent strategic initiatives and sustained competitive advantage: A review and synthesis of the literature. MIS Quarterly, 29(4), 747-776. doi: $10.2307 / 25148708$

Poba-Nzaou, P., \& Raymond, L. (2013). Custom development as an alternative for ERP adoption by SMEs: An interpretive case study. Information Systems Management, 30(4), 319-335. doi:10.1080/10580530.2013.832963

Prasad, A., \& Green, P. (2016). On information technology competencies for collaborative organizational structures. Communications of the Association for Information Systems, 38, 377-399. doi:10.17705/1cais.

Prasad, A., Green, P., \& Heales, J. (2012). On IT governance structures and their effectiveness in collaborative organizational structures. International Journal of Accounting Information Systems, 13(3), 199-220. doi:10.1016/j.accinf.2012.06.005

Queiroz, M., Coltman, T., Sharma, R., Tallon, P., \& Reynolds, P. (2012). Strategic IT alignment: An evaluation and process-level reconceptualization of the construct. Academy of Management Annual Meeting: The Informal Economy (pp. 1-32), Austin, Texas.

Ragowsky, A., Licker, P. S., \& Gefen, D. (2012). Organizational IT maturity (OITM): A measure of organizational readiness and effectiveness to obtain value from its information technology. Information Systems Management, 29, 148-160. doi:10.1080/10580530.2012.662104

Raisch, S. (2008). Balanced structures: Designing organizations for profitable growth. Long Range Planning, 41(5), 483-508. doi:10.1016/j.lrp.2008.06.004

Raymond, L., Bergeron, F., \& Croteau, A.-M. (2013). Innovation capability and performance of manufacturing SMEs: The paradoxical effect of IT integration. Journal of Organizational Computing and Electronic Commerce, 23 (3), 249-272. doi:10.1080/10919392.2013.807714

Reich, B. H., \& Benbasat, I. (1996). Measuring the linkage between business and information technology objectives. MIS Quarterly, 20(1), 55-81. doi:10.2307/249542

Reich, B. H., \& Benbasat, I. (2000). Factors that influence the social dimension of alignment between business and information technology objectives. MIS Quarterly, 24(1), 81-113. doi: $10.2307 / 3250980$

Reynolds, P., \& Yetton, P. (2015). Aligning business and IT strategies in multi-business organizations. Journal of Information Technology, 30(2), 101-118. doi:10.1057/jit.2015.1

Ribeiro-Soriano, D., \& Urbano, D. (2009). Overview of collaborative entrepreneurship: An integrated approach between business decisions and negotiations. Group Decision \& Negotiation, 18(5), 419-430. doi:10.1007/s10726-008-9134-x
Robey, D., Im, G., \& Wareham, J. D. (2008). Theoretical foundations of empirical research on interorganizational systems: Assessing past contributions and guiding future directions. Journal of the Association for Information Systems, 9(9), 497-518. doi:10.17705/1jais

Saldaña, J. (2015). The coding manual for qualitative researchers (3rd ed.). Thousand Oaks, CA: Sage Publications.

Siggelkow, N. (2007). Persuasion with case studies. Academy of Management Journal, 50(1), 20-24. doi:10.5465/ amj.2007.24160882

Sirmon, D. G., Hitt, M. A., \& Ireland, R. D. (2007). Managing firm resources in dynamic environments to create value: Looking inside the black box. Academy of Management Review, 32(1), 273-292. doi:10.5465/amr.2007.23466005

Sirmon, D. G., Hitt, M. A., Ireland, R. D., \& Gilbert, B. A. (2011). Resource orchestration to create competitive advantage. Journal of Management, 37(5), 1390-1412. doi:10.1177/0149206310385695

Tallon, P., Queiroz, M., Coltman, T.-R., \& Sharma, R. (2016). Business process and information technology alignment: Construct conceptualization, empirical illustration, and directions for future research. Journal of the Association for Information Systems, 17(9), 563-589. doi:10.17705/1jais

Tanriverdi, H., Rai, A., \& Venkatraman, N. (2010). Research commentary-reframing the dominant quests of information systems strategy research for complex adaptive business systems. Information Systems Research, 21(4), 822-834. doi:10.1287/isre.1100.0317

Tarafdar, M., \& Qrunfleh, S. (2009). IT-business alignment: A two-level analysis. Information Systems Management, 26 (4), 338-349. doi:10.1080/10580530903245705

Teece, D. J., Pisano, G., \& Shuen, A. (1997). Dynamic capabilities and strategic management. Strategic Management Journal (1986-1998), 18(7), 509-533. doi:10.1002/()1097-0266

Thorgren, S., Wincent, J., \& Örtqvist, D. (2012). Unleashing synergies in strategic networks of SMEs: The influence of partner fit on corporate entrepreneurship. International Small Business Journal, 30(5), 453-471. doi:10.1177/ 0266242610375292

Turner, N., Swart, J., \& Maylor, H. (2013). Mechanisms for managing ambidexterity: A review and research Agenda. International Journal of Management Reviews, 15(3), 317-332. doi:10.1111/ijmr.2013.15.issue-3

Van de Ven, A. H., \& Poole, M. S. (1995). Explaining development and change in organizations. Academy of Management Review, 20(3), 510-540. doi:10.5465/ amr.1995.9508080329

Vrontis, D., Thrassou, A., Santoro, G., \& Papa, A. (2017). Ambidexterity, external knowledge and performance in knowledge-intensive firms. Journal of Technology Transfer, 42 (2), 374-388. doi:10.1007/s10961-016-9502-7

Walsham, G. (1995). Interpretive case studies in is research: nature and method. European Journal Of Information Systems, 4(2), 74-81. doi: 10.1057/ejis.1995.9

Williams, C. K., \& Karahanna, E. (2013). Causal explanation in the coordinating process: A critical realist case study of federated IT governance structures. MIS Quarterly, 37(3), 933-964. doi:10.25300/MISQ

Yin, R. K. (2009). Case Study Research Design and Methods (4th ed.). Thousand Oaks, CA: Sage Publications. 


\section{Appendix A. Illustrative chain of evidence for CallCenter's SITA process}

\begin{tabular}{|c|c|}
\hline 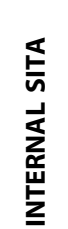 & 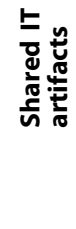 \\
\hline
\end{tabular}

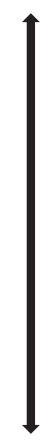

ISPartner has 525 customers in the world ... The largest surveyors have this software solution [...] which allows the complete management of a call center[...]. It often happens to give a helping hand on programming ... "Have you ever done this type of project that requires this ... this ... or this ....". So, yes, we talk a lot and we give between us advice in addition to having the technical support of our developer. There are far less expensive solutions on the market, even free solutions... We could do pretty much the same thing and [...] without doing a lot of $R \& D$ to get there, but hey! [...] we would have no interest in using this type of technology because it would cut off a portion of the business, we are currently doing by outsourcing [for and with] people who are currently on the same IT platform. (source: Owner-manager - November 28, 2013)

... for IT development ... In fact, the first step is "we need to improve on something" or "we have a problem and we need a solution". (source: IT Manager - December 6, 2013)

My passion for this kind of thing is contagious! [...] It started with the IVR, knowing that we had the technological infrastructure, that we also had the telephone lines... Following this little project, which stemmed from a special request from a client, we explored [...] in $R \& D$ to complete a brand new project that is quite innovative ... We should be able to implement after the holidays. [...] Always with the same customers [in collaboration with people who work or have worked at ISPartner]! (source: Owner-manager - November 28, 2013)

There's me as general manager. We have an operations manager. We have an IT manager and an analyst. Add to that, at the technical level, external resources, yes. (source: Owner-manager November 28, 2013)

I sat down with him and I said: "We need this and this ... ". And I said that it was maybe a couple of my ideas, of which I hadn't had the time to talk about [with them], but I knew what was needed. Then I had them add a couple of things and it went well ... Our agents accepted it well and our management team was happy. (source: IT Manager - December 6, 2013)

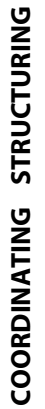

If we can successfully integrate all of these operations in terms of both functionality and efficiency, such that the customer is satisfied, this will probably bring us into another league. [...] There is nothing sexy about the IVR. It has been around for a long time. It's just about bringing it up to date and applying it creatively. (source: Owner-manager - February 4, 2014)

[With the new project management tool] there are a bunch of functions that are automated and that provide us with a real good dashboard, one that separates the different tasks assigned to each person with their deadlines. Also, we can see the time spent on each task, which facilitates things greatly with regard to billing. It is thus an interesting functionality with regards to the control of a project. (source: Owner-manager - June 14, 2014)

With regard to the programming of the projects, I can do my part while the operations manager does his part. Everyone must know to a certain extent ... each part of the equation ... (source: Ownermanager - February 4, 2014)

In terms of purely technical infrastructure, we have everything we need. It's really at the level of the organizational [level] that things happen [now]. (source: IT Manager - December 6, 2013) 